\title{
Social Capitalism: A Descriptive Sketch
}

\section{David A. Westbrook}

I wish to discuss political economy in some rather idiosyncratic ways. For those of you with jobs in finance or related fields (in which I teach), please do not take anything said here too seriously, as that would be professionally irresponsible. That was a joke, sort of. There are basic ways that we as a society think about, and professionally certify, participation in our economy. Normative political thought, and therefore teaching, proceeds on a generally implicit presumption that the terrain (topoi) is fairly well mapped, the topic understood, not least by the teacher, and the questions concern what is to be done and how our goals, either for would-be practitioners or for society writ large, are to be accomplished by well-meaning mandarins.

Like any orthodoxy, such understandings of political economy entail a series of imaginations about our world. Many people are happy with the world as they perceive it, for whatever reason, and justify it in conventional ways. Most, but not all, of this happiness is nowadays called conservative or politically "right." Many other people are not so happy about this state of affairs. Whatever their actual reasons - which, again, need not concern us here - such people, dominant in certain precincts of the university, tend to express their discontent, also in familiar ways called "left."

* This essay introduces, and roughly summarizes, my thinking on political economy done, mostly, since the Global Financial Crisis. Thanks to John Henry Schlegel for a typically good reading and David Pan for thoughtful editing. The failings remain, as always, my responsibility.

1. I have been told that this essay reminds some readers of the late Martin Sklar, the very influential yet relatively obscure historian of and political thinker on the United 
Thus, a great deal of political discourse proceeds on a politely assumed description of the economy, what we learned in graduate school, read in the Economist, whatever. Our political differences are largely explained by our convictions, allegiances, identities-feelings.

Suppose, à la Jonathan Swift, that our description of our own economy is a well-mannered joke, or at least would be funny to an alien visitor? ${ }^{2}$ Suppose we think it all wrong, and so what we say is more or less nonsense? The imagery of "left" and "right," used as self-evident and transcendent conceptual categories in arguments today, is an artifact of the French Revolution, now almost a quarter millennium old. ${ }^{3}$ Most of the thinking that we now recognize as "left" or "right" is nineteenth- or early twentieth-century thinking, which used more or less refined descriptions of a different world to make very different arguments. None of which is to say that historical thought is not important — good thinking is always important - but it is to say that one should be careful. If the Global Financial Crisis (GFC) taught anything, after "the entire edifice collapsed," it should have taught that much received "wisdom" is just silly, that even very educated people often have no real sense for what they are talking about and simply do not know how familiar language links up with our strange world as it is, somewhere "out there" beyond the morning's media intake. ${ }^{4}$

States. Theretofore, I was largely unaware of Sklar's work, certainly did not study it, but some subterranean influence might be possible. Having since looked into the matter, I do see affinities between what I am attempting and various arguments made by Sklar, particularly his notion of the "disaccumulation of capital," i.e., at some point in a technological society, growth is no longer logically related to inputs of either labor or capital and may occur without more substantial investment. There are of course also differences. Sklar was much more committed to the conceptual grammar, and especially to the vocabulary, of the traditional left than I am. More deeply, Sklar seems to me an ideological thinker, in the literal sense of starting with ideas (e.g., "the left" or "capitalism") and searching for the ways such ideas are expressed in social practices at this or that time and place. I tend to work in the other direction, "critically" perhaps, by examining social practices, usually contemporary, and asking what ideas are implicitly entailed. Sklar's death prompted a number of appreciative assessments, notably "Symposium on Martin J. Sklar," Telos 186 (Spring 2019): 97-185.

2. See Jonathan Swift, Gulliver's Travels, vol. 36 of The Great Books of the Western World, ed. Robert Maynard Hutchins (Chicago: Encyclopedia Britannica, 1952), pp. 1-184. Any section would do.

3. Simon Schama, Citizens: A Chronicle of the French Revolution (New York: Random House/Vintage Books, 1989), p. 479.

4. See David A. Westbrook, Out of Crisis: Rethinking Our Financial Markets (Boulder, CO: Paradigm Publishers/Routledge, 2009). 
Learning is hard and memories are short, however, so faith in ordinary science has made a comeback over the last decade, and the mediasphere is a cacophony of received ideas. Things now confidently expressed on both the "right" and the "left" are not so much wrong or illogical as inapt and awkward, like rumors of conflicts in another country. These are things we know how to say, however, and things other people know how to hear, and so argument may proceed apace. Indeed, moralistic argument and hence self-presentation in the face of alienation may be the point, as recent elections in the United States and elsewhere, and the pious effusions of the middlebrow press, suggest.

If contest is the point (reason is the slave of the passions, with a vengeance), then it would be foolishly intellectual to ask: what might a better imaginary for contemporary political economy look like? Fools rush in, so this essay introduces and roughly summarizes my thinking on these matters for many years now, mostly since the GFC. While a full description and defense of these ideas would require a long book, I hope the following four interrelated terms are enough to suggest a better map for our economy, and therefore put us in a better position for simple understanding and maybe even - to dream-more reasonable if not classically enlightened policy discussion.

The four terms are:

- social capitalism (a sociological description)

- abstract economies (an operational description)

- from contract to status (resulting class structure and identity)

- custodial regulation (political norms)

\section{Social Capitalism}

In "modern" political thought since at least Hobbes, society has commonly been imagined in terms of cognate oppositions: the king and the people; the state and the individual; the law, with its power to tax and spend for defense and other aspects of social welfare, vis-à-vis the market, which produces goods and services. ${ }^{5}$ Sticking with the English, we see this opposition institutionally expressed by the King, who borrows, 
and the City, the goldsmiths, bankers, and later the Bank of England, who lend to him. ${ }^{6}$

In the nineteenth century, Marx sought to dissolve this oppositionthe means of production, hitherto largely private, would be owned by the state in the name of the proletariat, and in the sweet by-and-by, the state itself would wither away. But even Marx started from the traditional political assumption of an opposition between those who own and rule (the bourgeoisie, sometimes expressed as a state, sometimes not) and those who labor and are ruled, the people writ large. ${ }^{7}$ The Marxian dream was to dissolve this antinomy, and the Soviet Union, China, and other places tried to achieve that dream, or at least professed to. At the end of the last century, the dream was abandoned even in name, and countries that had espoused Marx became openly capitalist, albeit in various ways. In the West, this was widely seen as a triumph of "the market" over bureaucratic planning, and it was.

Market triumphalism, however, obscured deeper truths about the structure of modern societies that can only misleadingly be imagined in terms of the centuries-old dualities. This is clearest in the United States, where education, healthcare, retirement, various forms of insurance against loss or even death, the arts, and spiritual life are routinely provided by "private" institutions, often with large endowments. Even "public" institutions, such as my university, receive only limited support from the taxing power of the state - the budget is largely comprised of fees and endowment returns. More generally, in the United States, the public functions of social life are often directly dependent on markets, and especially capital markets.

In most other countries, the state takes more direct responsibility for social welfare. Even in such countries, however, the state requires access to debt markets in order to make good on its promises, as the European debt crisis made clear. In Europe and elsewhere, the welfare state and its tax base presume a certain kind of economy that is largely guarded and guided by central banks. Conversely, central banking entails an imagination of political economy. The legal mandate of the U.S. Federal Reserve

6. For an amusing account of relations between the King and the City in early modern England, see Moshe Arye Milevsky, The Day the King Defaulted: Lessons from the Stop of the Exchequer in 1672 (Cham, Switzerland: Palgrave Macmillan, 2017).

7. Any number of places, but very clearly: Karl Marx and Friedrich Engels, "Manifesto of the Communist Party" [1888 ed.], in The Marx-Engels Reader, 2nd ed., ed. Robert C. Tucker (New York: Norton \& Co., 1978), pp. 469-500. 
is employment and monetary stability (with moderate term interest rates thrown in as a kind of capitalist version of price stability). The German Bundesbank and hence, historically speaking, the European Central Bank have emphasized price stability. Such goals require institutional stability, and so, notably, the lender of last resort function. And some degree of growth has emerged as a sort of shadow goal, implicit in the others. In other words, the state's provision of social welfare depends upon an ability to tax and sometimes to borrow, which in turn depends on a tax base, at least modest growth, and sound credit, in turn again dependent upon relatively good governance, especially monetary - a virtuous circle, on good days, in which "public" and "private" are mutually imbricated. To play on the Marxian imaginary, the people did not ascend to power and become public, losing their private selves (the "dictatorship of the proletariat"), but instead private action came to be recognized as, already, social governance, if not precisely the state.

The idea that markets are governance mechanisms was made explicit during the GFC, when governments around the world rescued their banks. It has long been recognized that banks, through the payment system, fill key social roles - hence much bank regulation, and in particular the lender of last resort function, which gives the central bank (or sometimes the state), the ability to rescue a bank, i.e., to use "public" money to save a "private" institution, in order to prevent panic. In the GFC, however, the state's effort to right the economy hardly stopped with banks. Other sorts of institutions, e.g., General Motors, were rescued. Interest rates were held low, making commercial and retail lending cheap. So-called "stimulus money" was distributed in various ways. One might go on, but the general point is that the U.S. government and states throughout the world (including China) operated through the "private" sector, variously with tax dollars, sovereign debt, fiat currency, and adjusted regulation, i.e., sovereign perquisites, rendering the "private" no longer very private. In some cases, the government even received large ownership stakes in entities hitherto thought of as nongovernmental, though nobody said the word "nationalize," at least in the United States. In return, the private sector was expected to continue to conduct itself in orderly fashion, indeed, to create order, and in that civil sense, govern.

Countries around the world responded to the COVID-19 pandemic in structurally similar ways. Governments worked to get business and individuals sufficient funds to meet their obligations. (The mismatch between 
regularly timed obligations, e.g., rent or payroll, and irregular income, e.g., sales, bears some resemblance to the mismatch between long-term assets and short-term obligations at the heart of bank runs.) Similarly, ordinary laws, e.g., foreclosure and eviction, were temporarily suspended. Central banks provided unprecedented levels of money, and taxes were forgiven. To generalize, states worldwide have worked to preserve markets through the provision of capital and the forgiveness or at least delay of debt obligations, precisely because markets provide the overwhelming majority of social welfare. By this point, however, it makes little sense to think of "the market" in any rigorously private fashion. Capitalism has been socialized.

As will be further discussed below, even in ordinary times, economic operations depend on well-functioning credit markets. The so-called "real economy" runs on credit. Consider, in this regard, household credit cards, various forms of electronic transfer, commercial paper markets, and credit facilities offered by banks to firms to make payroll. Indeed, even cash, the payment system, and ultimately the institution of money itself require the health of leveraged financial institutions. Once the functioning of the "ordinary" economy is understood to require smoothly operating capital markets, then the venerable tendency to understand finance as extraordinary (used to achieve something that the borrower cannot or will not pay for out of retained earnings, at least not immediately, such as the purchase of a house or a company) becomes less significant. Simply put, the daily life of modest individuals requires the financial economy to be functioning reasonably well, or else they do not get paid and cannot buy milk for their children.

Understanding the extent to which capital suffuses contemporary societies has profound consequences for political economy. The traditional distinction between labor and capital loses much of its normative force. Those who labor, like those who own, are dependent on capital markets, albeit in different ways. Indeed, people who work are also, generally, rentiers. (Most readers of this text would fall into this category.) "The social" (once thought to be workers and their dependents) cannot be understood in simple opposition to capital, despite drastic increases in inequality. Most obviously, workers are dependent on capital markets to secure their retirements. As I like to tell my students, you're all capitalists now-if we get you a job, you will be invested.

Even more significantly from a humanitarian perspective, over fifty percent of the U.S. population does not work for a wage. Consider the 
average lifespan. The young and the old do not work, or not much, and as a society we have mightily extended both youth and old age. Prisoners, the homeless, and many of the sick or otherwise infirm are generally unemployed. Similarly, the ordinary unemployed, the underemployed, caregivers who do not have day jobs, or the affluent who do not bother are not, by and large, paying their way by the sweat of their brow or the cleverness of their brains. All such people are directly dependent on their status, which, as we shall see, means dependent on capital markets, or dependent on institutions that are directly dependent on such markets. And, as the COVID-19 pandemic demonstrated, many people's jobs are redundant, to use the English phrase. A humane political economy must see to these people, too, but it cannot do so by reliance on labor markets ("we will retrain them to earn a place in the internet economy"?) much less an opposition between labor and capital. Thus, among other things, seriously understanding the capitalization of social life pretty much ends the geometry of traditional "leftist" thought, at least understood as an analytical, critical, or practically political enterprise. The question, preliminarily discussed below, is what will take its place. Attempts to realize humane sentiment, what in some contexts used to be called solidarity, require a new and more capacious grammar.

\section{Abstract Economies}

For reasons of intellectual history (or perhaps better, psychology) beyond the scope of this essay, economics traditionally has built upon very simple, hypothetical yet concrete models and then worked toward grand theories. So, for example, one man has more apples than he can consume, and another has extra wheat. They meet and exchange what they do not need for what they want. They both leave happier than when they met, and the world is better. (Since Adam Smith at least, the scientific enterprise has quickly spawned a normative political project, or maybe the other way around. ${ }^{8}$ Perhaps our hypothetical traders agree to meet again at a certain time and place, and thereby establish a market. Or to use shells as a medium of exchange, establishing money. That sort of thing. Soon enough

8. Adam Smith, An Inquiry into the Nature and Causes of the Wealth of Nations, vol. 39 of The Great Books of the Western World, ed. Robert Maynard Hutchins (Chicago: Encyclopedia Britannica, 1952), pp. 1-184. It is worth remembering that Smith, from the beginning, was attempting to put a political policy on a scientific footing. Intellectual dangers abound. 
one is talking about specialization-who makes the pins, who makes the wine - and efficient exchange, again to recall Smith.

Explanation of the class of financial instruments known as derivatives almost always begins with a farmer who is uncertain of a future harvest, or perhaps the price of grain at the time of harvest, and who seeks to lock in a return. So, perhaps he offers to sell some amount of grain, at a price fixed today, for future delivery. Suppose the sale price is related to the open market price? Suppose we standardize the terms and allow for cash settlement of the value of the contract in lieu of delivery? Suppose we allow trading on exchanges? In a jiffy we may be talking about a market "in grain" that is far larger than the year's supply of grain. The global foreign exchange markets (ForEx) trade more in a month than the global GDP for the year. Whatever the financial markets are, they are not very "material." More generally, while economics as a discipline seeks to be as simple and concrete as possible, economic life works in the other direction.

Consider a trip to the grocery store. Perhaps, in the COVID-19 era, you have an app on your phone. You place an order, listing various things you want. You push "pay," and presumably your "credit card number"which your eye cannot read, translated as it is through layers of machine language and one hopes encrypted - is sent to the store, maybe this store. Well, somewhere. Maybe several places. Maybe there is further communication about your creditworthiness. Or maybe some intermediary (the parent corporation, a bank, the vendor of the app, there are many possibilities) has taken on your credit risk. How shopping apps work is hardly clear, and they need not all work in the same way. While you are pondering such questions, your phone bings to tell you that "payment" has been "accepted," by somebody, one supposes, but maybe not a natural person. Maybe you have been billed already, yet perhaps you could still deny the charges. Or not. If this is a "debit" card... "You should arrive between 1:00 and 2:00 to pick up your groceries. Call when you get here and we will bring them out." Questions unanswered, you arrive at the local store, and some kid named Jack (not "we," but presumably an employee of the store, an agent) loads actual food into your car, says "you're all set," and slams the door, ignoring the button that activates a servo motor that would close your door, gently. You drive off, legally.

It is unclear what all just happened, but one thing that did not happen was "an exchange." You did not give Jack anything. Instead of actual exchange, various accounts on various computers were changed; i.e., by 
"payment" we usually mean a string of communications containing legally binding promises to account. In this example, on the seller side, there are objects, groceries, although few of the parties involved will touch anything so tangible. Most of what is "exchanged," even in a grocery store transaction, does not exist in any material sense. "Exchange" has itself become a metaphor for essentially legal communication about the terms of financial instruments, promises to alter numbers that, like sports statistics, express relative standing. For Marx, capital relations, founded on money, would replace the often brutal but concrete, authentic relations of feudal society. "All that is solid melts into air," he famously said. ${ }^{9}$ Dematerialization - our ability to replace the world with its simulacrum - has continued since, until even buying groceries happens in "the cloud," which is itself a metaphor.

The capitalization of social life, discussed in the preceding section, is mirrored and indeed made possible by the abstraction of contemporary economies. For example, in recent decades, many markets in concrete assets and specific obligations, ranging from houses to much compensation to pensions, have been replaced by markets in more liquid legal instruments, resembling shares of stock, freely tradeable, and sometimes exchange traded. This is what securitization is: obligations tied to assets, e.g., mortgages on houses, credit card debt, whatever, are pooled, and interests in the pool of various sorts, usually designed around payout structure and risk, are sold. The concrete assets, houses and the like, disappear from view.

Similarly, a balance sheet may be naively understood as a "snapshot" of a corporation or other entity. Admittedly, a corporation is a legal and thus spectral thing, but we often think we can "see" it in the world. Companies tend to have a headquarters, a logo, people who identify themselves with the firm, and so forth, all of which indicates Acme Corp., as the Roadrunner has it. But with "special purpose entities," the assets and liabilities of a firm can be transferred to other firms almost at will. The borders move; the size of Acme is uncertain. For contemporary accounting, there is no simple "thing in the world" to represent. One cannot say Acme simply owns $\mathrm{X}$, owes $\mathrm{Y}$, and therefore has equity $\mathrm{Z}$. Instead, "the firm" is a nexus of legal relationships, and what counts as ownership, or what contingent liabilities ought to be booked, is now unclear. The precise

9. Marx and Engels, "Manifesto of the Communist Party," p. 476. 
scope and durability of that nexus, under what circumstances, is a matter for professional dispute.

If the contemporary is characterized by the abstraction of the concrete, pervasive vaporization, it is also characterized by trade in things that were never concrete. Consider, most obviously, digital media and services. Information about us is hoovered up by our devices and auctioned off without ever becoming concrete, or even deniable. Or consider socalled "financial assets," ranging from the aforementioned debt securities to stocks to derivatives to any number of other animals in the financial jungle, without ever becoming some thing. Indeed, many of the economic indicators to which people pay a great deal of attention, notably the stock market and the wealth of individuals like Jeff Bezos (Amazon), are largely functions of movements in the collective assessment of the relative value of financial assets - all the action is on the left side of the balance sheet. A stock stake nominally "worth" a hundred billion dollars cannot be comprehended in terms of "stuff" but must be compared to other abstractions. And so, it is far from clear what the statement "Jeff Bezos is the wealthiest person on earth" actually means, other than numbers beyond precise reckoning. ${ }^{10}$

One might think that Bitcoin and other digital currencies, based simply upon mathematical problems constrained by computing power, might represent the ultimate expression of the contemporary economy's tendency toward abstraction. There is truth in that, but digital currencies are probably better understood in the opposite direction, more like gold, a protest against the galloping compounding uncertainty of the contemporary, often demonically embodied by fiat currency generally and central banking in particular. The math underlying digital currencies is said to be sound, i.e., there can only be so much Bitcoin, and it takes enormous amounts of computing power to "mine" it reliably. While there are many computers involved in this enterprise, they are at least in theory transparent to one another (the ledger is open). The question raised by Bitcoin is not how abstract may markets be, but what is the extent of abstraction that we can stand? And that may be a question for central banks of the future, too, if they exist.

10. David A. Westbrook, "Climbing to $10^{11}$ : Globalization, Digitization, Shareholder Capitalism and the Summits of Contemporary Wealth," in The Inequality Crisis, ed. Edward Fullbrook and Jamie Morgan (Bristol: World Economics Association, 2020), pp. 312-45; previously published in Real-World Economics Review 92 (June 2020): 151-66. 


\section{From Contract to Status}

During last summer's Black Lives Matter protests, demands for equality were widespread and loud. But equality is one of those surprisingly difficult words, like "truth" and "security," that usually are understood indirectly, through negation. While it is difficult to define equality, truth, or security as such, racial discrimination, falsity, and violence are more easily recognizable and entail a notion of their positive opposites, which might seem to be enough for most political purposes.

Progress, Henry Sumner Maine famously wrote, consists in the historical movement from societies in which order was defined by status or birth to societies in which order was defined by contract. ${ }^{11}$ The point was that ancient social structures were built on status: who one was as a member of a group, defined by gender, caste, race, or some other category recognized by law, most notably "slave." The modern era, in contrast, is defined to be "modern" insofar as social structure is built from individual promises (by contract, especially employment) and, by extension, who one is, in some deep sense, as an individual. Something like this is what is meant by "liberal," and a great deal of "progressive," in contemporary American political discourse.

Indeed, (in)equality may be the primary (ultimately conservative) mode of legitimation in the United States and other contemporary capitalist societies, eclipsing freedom. Wounding criticism of the status quo, for example, denigration of the contemporary university, is often characterized as nostalgia for an era of racial or other injustice, and hence simply inadmissible in polite/moral discourse. Self-styled progressives often maintain that we cannot hear such critique lest we return to status as the basis of our social order, and therewith slide "back" into injustice.

This imaginary of the contemporary world celebrates equality as its very heart, at least the capacity to contract, equality "before the law," as Kafka might have it, and as the republican imagination ("social contract") would like to have it, too. Traditional economics employs much the same imaginary. The man with wheat and the man with apples who enter into a willing exchange are, by the terms of this state-of-nature story, "equal." They voluntarily, and we must presume fairly, trade apples and wheat; neither has an advantage of which we are told, nor does one simply take the property of the other. That is, the free exchange in a state of near-nature

11. Henry Sumner Maine, Ancient Law: Its Connection with the Early History of Society and Its Relation to Modern Ideas, 16th ed. (London: John Murray, 1897), p. 170. 
through which we think through political economy seems to entail equality, so that our idealization of the market mirrors our idealization of the social contract. In light of the fact that material inequality is rising worldwide, "equality" is a convenient normative standard with which to conduct critique that sounds like politics, an argument for what is to be done.

All of this is familiar enough, but is it our world, sometimes seen more clearly through "fiction"? The Kafka parable is disturbing. ${ }^{12}$ A man from the country seeks entrance to the Law, but encounters a doorkeeper. Although the door is open, the doorkeeper does not give the man permission to enter. The man from the country is even invited to try to enter without permission, but he does not do so, perhaps because he is told to "just try," and further told of doors beyond, with yet more fearsome doorkeepers. The man pleads, bribes, waits, "days and years," and ages, but permission is not forthcoming. Shortly before he dies, the man from the country gathers himself to ask, "Everyone strives to attain the Law ... how does it come about, then, that in all these years no one has come seeking admittance but me?" Seeing that the man is dying, the doorkeeper "bellows in his ear: No one but you could gain admittance through this door, since this door was intended for you. I am now going to shut it." The man from the country is alone, and has been since he arrived before the Law. His situation before this door, at the very least, is unique, singular. There is nobody for him to be equal to, certainly not the doorkeeper, only the lowest figure of authority, if far too much for the man from the country. What, then, does equality before the Law even mean, here?

It is hard to imagine a relevant sense in which the grocery shopper is equal to the app designer, or the several banks, the national corporation, or the local franchisee (meaning variously its management, its board, its shareholders, or its employees and other stakeholders). Most of the parties to this transaction are not even human: legal fictions, ghosts perhaps, but economic actors all the same. As suggested in the foregoing section, transactions comprise chains of communication and promises to account. The question, for the participants in the transaction, is not equality but authority. Jack does not load groceries because he is equal to the buyer. He loads groceries because he is the employee, the agent, of the seller. He is authorized to take groceries and load them into a stranger's car. If he does not do so, he will lose his job.

12. Franz Kafka, The Trial, trans. Willa and Edwin Muir (New York: Schocken Books/ Random House, 1984), pp. 213-15. 
Conversely, you, the shopper, cannot buy groceries just because you are not discriminated against. You can buy groceries because you have "money"-which sounds like a thing but is actually a status, positioning you with authority vis-à-vis certain institutions in such a way that you can tell them to credit other institutions, more agency relations. The law of agency was once, more honestly, called "master and servant." Equality has almost nothing to do with our actual practices, and for analytical purposes is often a distraction, reassuring us of our morality. None of this is to say that inequality - meaning discrimination on the basis of an invidious classification, e.g., race - is not important, often heartbreakingly, even fatally, so. It is a good thing that Jack is not discriminated against for being black, or gay, or a Muslim, or what have you. It is to say, however, that our understanding of our political economy cannot get very far with "equality" as an analytic concept.

A republican mind (like mine, still) might wish to save the imagination of a contract between equals, in essence, to think of the social, even the economic, in terms of republican citizens, equal as such, and with the autonomy at the heart of "liberal." And perhaps this imaginary can be sustained, even today, in important contexts, such as electoral politics or trials. But the task is harder in the context of political economy. One might point out that agency is legally defined as a consensual relationship; Jack consents to the employment contract. It is true in the United States in fact but a distraction in principle to note that uncertainty about healthcare and other benefits forges handcuffs out of employment contracts. The problem, in principle, is that participation in such "consensual" relations cannot be avoided if one is to participate in contemporary social life. Indeed, in many totalitarian systems, the consent (or confession) of the subordinated is required, for dramatic closure and the glory of the regime. In a digitized world, we "consent" to things we cannot understand every day, and we facilitate our own surveillance, witness our own obedience, because what choice do we have?

To make the same point differently, one might say that the purchase of groceries involves an "exchange" of permissions, immaterial rights and obligations, among actors with the legal capacity to contract. For historical reasons, we tend to conceive of exchange in terms of "real" property, i.e., land, and chattels (from "cattle") and natural persons. Nowadays, we often deal in intangible "intellectual" property, digitalized ephemera, exchanged among legal persons, few of whom breathe, even when buying 
the evening's dinner. The problem here is that if we so broaden the notion of "exchange," then any society may be understood in terms of exchange. As Marcel Mauss demonstrated, such exchanges may be understood in terms more or often less like microeconomics has been understood in the tradition running from Adam Smith. ${ }^{13}$ So, one might say, the vassal exchanges duties of loyalty and labor with his lord, who is thereby obligated to protect the vassal. Indeed, the lord is the vassal of the king and "works" on his behalf-fighting his wars, siring the next generation of the aristocracy, that sort of thing, but nobody obeys the duke because of his hard work, and nobody talks about equality, apart from that of souls before God. In our own time, it is not clear that investment in high-tech firms, in which shareholders have no effective ownership, is not closer to the potlatch than to the exchange of apples for wheat among equals. More abstractly, in order to describe the socioeconomic relations we have in fact, the notion of exchange must be broadened to the point that it no longer implies the republican imagination of social life-which suggests that contemporary social life may not be republican in structure, and liberal notions about autonomy and contract may be formally, or trivially, true, but really just silly.

Suppose, in moving from the antithesis of capital and labor to social capitalism, from an economy of goods and services to an abstract economy, we have also moved from contract back to status as the foundation of social order? Perhaps it is wrong to frame such thoughts as historical development. Marx and Maine may have been more or less wrong in their descriptions of society in their own days, questions that will not be explored here. Without a baseline, however, one cannot ascertain how much has changed. But the degree of change is not the pressing issue. The question is whether we are neo-feudal and have not yet awoken to our lives.

\section{Custodial Regulation}

If we look at the long arc of North Atlantic political thought conventionally dated from Hobbes, this sketch suggests a fundamentally different Weltanschauung, and is in that sense postmodern (a term one hesitates to use, even after the deluge of ink has subsided). Post something, at any rate,

13. Marcel Mauss, The Gift: The Form and Reason for Exchange in Archaic Societies, trans. W. D. Halls (New York: Norton \& Co., 1990). For application to contemporary markets, see Amy Deen Westbrook and David A. Westbrook, "Snapchat's Gift: Equity Culture in High-Tech Firms," Florida State University Law Review 46, no. 4 (2019): 861-908. 
leaving us to ask how might we think about political economy, governance through markets, after republican pieties have been washed away in a sea of liquidity, or, to put it more bluntly and in European terms, after austerity has shown what matters. A few things already seem clear.

The capitalization of social life should mark a fundamental shift in social thinking, even for those who style themselves as progressive or on the left. The task for a humane political economy is not to oppose capital in the name of labor, conflated with humane sentiment; the task is to construct capital markets, indeed markets more generally, that serve people. In this view, economic regulation should be understood as constitutive of core social processes. Markets are not an alternative to government or politics, but instead a form of political life, and should be evaluated, and developed, accordingly. Markets are not only how we respond to financial crises, as in the GFC, but how we have responded to the biological crisis of COVID-19. Contra the old Soviet Union, markets are preferred mechanisms for social choice in many-by no means all! - contexts. Contra the market triumphalism that has been so powerful in the United States over the last two generations or so, the purpose of regulation is not solely to correct for the failure of some natural market (usually phrased as internalizing the costs of negative externalities). Instead, as with the rules of a game, the general object of regulation is to design contexts in which relatively autonomous actors competitively and cooperatively pursue individual success and thereby produce social goods. ${ }^{14}$

Contemporary economic life is now largely if not entirely digitally mediated. Even something as simple and one might think concrete as buying groceries tends to involve a great deal of digital interaction, on top of digitally informed supply chains. Many but not all such communications involve or represent "money." Once money is understood in terms of accounting, obligations, claims, and so forth, however, the designation of this or that as money becomes less structurally significant, just another part of the web of communications and cultural assumptions (e.g., corporate ownership) that enables a given transaction. (Earlier versions of this thinking used the phrase "economies of money" instead of "abstract economies." $)^{15}$

14. This is the central thesis of Westbrook, Out of Crisis.

15. See, e.g.., David A. Westbrook "The Culture of Financial Institutions: The Institution of Political Economy," in Integrity, Risk and Accountability in Capital Markets: Regulating Culture, ed. Justin O'Brien and George Gilligan (Oxford: Hart Publishing, 2013), pp. 3-20. 
Conversely, however, finance, once thought to be managed by bankers and other stuffy people within a rather specialized world, has become omnipresent. A gas pump, or an EV charging station, is a financial institution. Under social capitalism, in an abstract, digitized economy, financial regulation writ large is also everywhere. Thinking about political economy as politics, as regulation, inescapably financial, should shift accordingly. The traditional enterprise, fostering the formation and allocation of capital, remains important. Far more important to most humans most all the time, however, is maintaining the stability of the institutions - now all perforce monetary institutions - on which contemporary social life depends, hence "custodial regulation."

Consider the financial world going into the GFC: a global society in which social commitments have been capitalized (notably retirement) and are held on a portfolio basis (think of a 401(k) investment in a fund) exposed to highly leveraged and interdependent institutions (think Citigroup or AIG). And it blows up. The traditional understanding of what finance is, and so how to regulate it - how efficiently to foster the collection of scarce capital from savers and to allocate such capital to worthy entrepreneurs while preventing fraud-does not account for the world exposed by the GFC, in which society itself depends on financial flows. Entrepreneurs do sometimes seek venture capital, innovate, and return profits to investors, what might be called the Silicon Valley story. Steve Jobs was a real person. But people buy groceries, digitally, every day, everywhere. Especially for those of us who teach finance, the Silicon Valley imagination of finance should lose its dominance and largely be replaced by a more custodial understanding of the vitality of stable capital to social order and humane understandings of institutions.

To elaborate, the managers of a pension fund, a university endowment, or even a bank's sovereign debt portfolio - rather than the venture capitalist and the entrepreneur - should become the paradigmatic figures for contemporary thinking about political economy generally and financial regulation more specifically. For such managers, the issue is fulfillment of fiduciary obligation, which requires the ability to deliver what and when promised. The paradigmatic fiduciary, the trustee, is the custodian of the beneficiary's interests; from a custodial perspective, finance is the mediation of existing social obligations among parties and across time. Growth is desired but hardly essential: the fiduciary obligation exists nonetheless. Should the relevant elites take this conceptual turn to social capitalism 
operating through an abstract economy, the aesthetics and practices of economic regulation will be different from those that have characterized the last several decades. Rather than an emphasis on risk-taking in the hope for creative destruction that, on balance, may be said to serve society's best interests, financial regulation in particular could become more explicitly concerned with the reliable flow of social capital.

\section{Conclusion}

This sort of essay traditionally closes with a prayer for better governance, styled as normative argument: "therefore, we must ." It is a strange trope, because widespread obedience to even the most masterful essay seems unlikely, indeed a misunderstanding of what an essay is. For a few people to gain slightly better understanding of our situation would be more than enough for a little under 7,000 words to accomplish. And perhaps it is an artifact of the Enlightenment to hope that politics be legible to itself, "right or wrong or indifferent," as a "professional soldier" friend of mine likes to say in the midst of a grisly story, and how am I to respond to that, rationally? Yet I am an American intellectual of a certain age, and I do not know what else to do but try to articulate our world, even if it is hard to call home, and I cannot help gesturing toward better politics if not exactly redemption. At least we can hope for jokes - that we have aplenty. 
Timely. Provocative. Independent.

Telos is a must-read for anyone with a serious interest in politics, philosophy, culture, and the arts. Subscribe now at www.telospress.com.
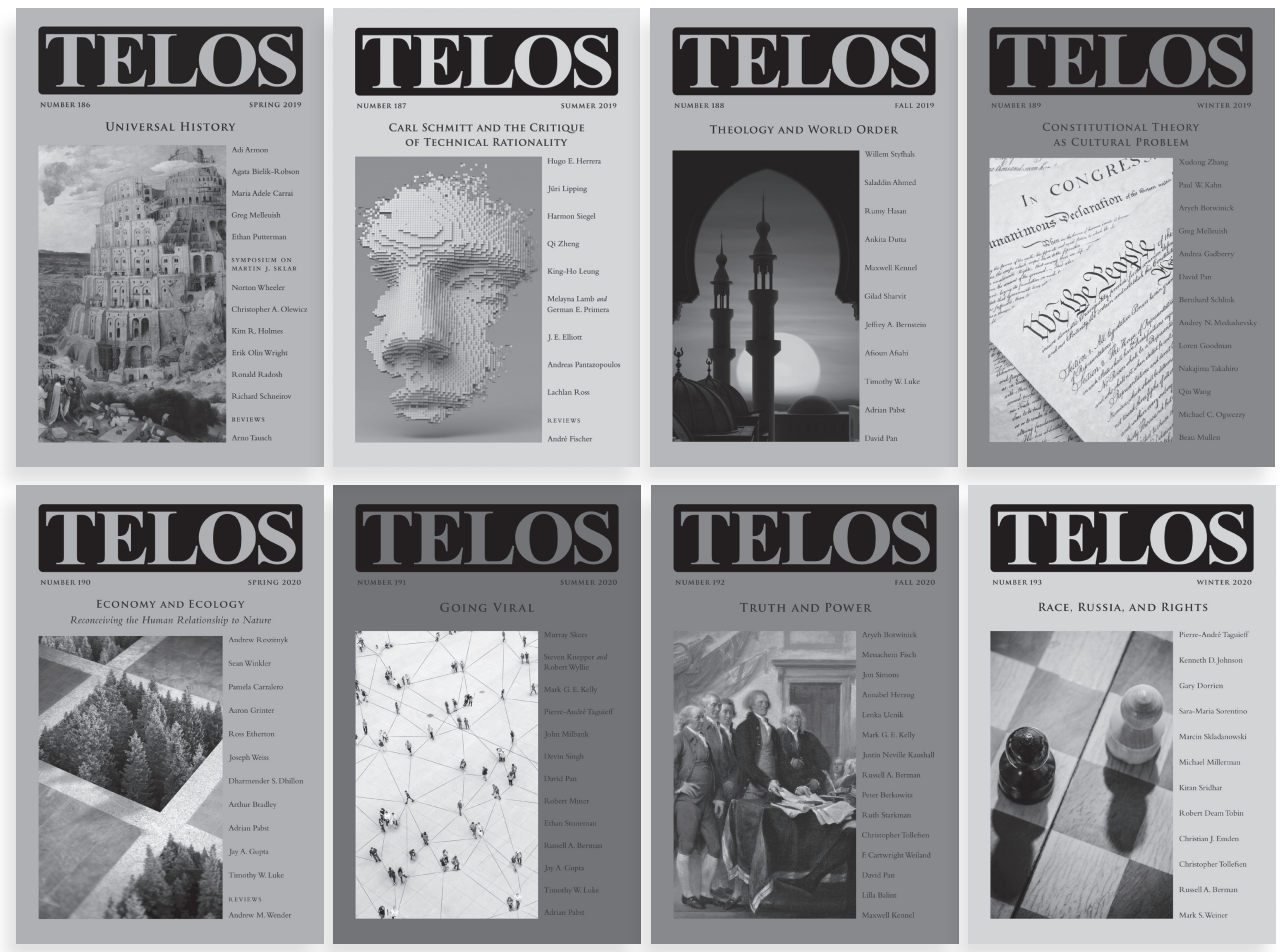

Since 1968, the quarterly journal Telos has served as the definitive international forum for discussions of political, social, and cultural change. Readers from around the globe turn to Telos to engage with the sharpest minds in politics and philosophy, and to discover emerging theoretical analyses of the pivotal issues of the day.

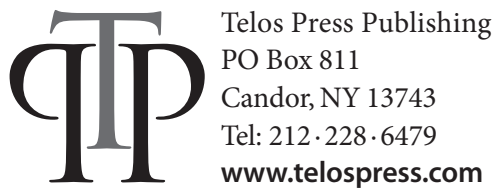

